\title{
Efficacy of Albendazole Mass Treatment Alone Compared to Combined Albendazole - Flubendazole Regimen for Treatment of Resistant Enterobius vermicularis Infection in Children Enterobius
}

Khaled A. Temsah"1, Doaa Abdel Fattah ${ }^{2}$, Amal A. El Kholy ${ }^{3}$, Mohamed Ibrahim Elsamanoudy ${ }^{4}$

Departments of ${ }^{1}$ Parasitology and ${ }^{4}$ Pediatrics, Faculty of Medicine, Al-Azhar University, Damietta, Egypt.

${ }^{2}$ Department of Parasitology, Faculty of Medicine, Al-Azhar University, Cairo, Egypt.

${ }^{3}$ Department of Clinical Pharmacy, Faculty of Pharmacy, Ain Shams University, Cairo, Egypt.

*Corresponding author: Khaled Aly Temsah, Mobile: (+20)01063282834; Email: drkhaled2008@ yahoo.com

\begin{abstract}
Background: Enterobius vermicularis is one of the most common parasitic helminths causing infection in children worldwide causing distressing lifestyle and health problems. The empirical use of anthelminthic drugs without medical supervision and low compliance to treatment protocols lead to resistance to therapy.

Objective: To assess the efficacy of albendazole mass treatment alone compared to the combined albendazoleflubendazole regimen for treatment of recurrent and resistant Enterobius vermicularis infection in children and their families.

Subject and Methods: It was a clinical trial that included 130 children 3-12 years old with resistant Enterobius vermicularis infection determined by the following inclusion criteria for treatment resistance. This study was carried out at the Pediatrics outpatient Clinic at Al-Azhar University Hospitals, and the Medical Parasitology Department at Damietta Faculty of Medicine, Al-Azhar University at New Damietta city, Egypt.

Results: 36 out of $65(55.4 \%)$ children in the albendazole treated group and 54 out of $65(83.1 \%)$ in the albendazoleflubendazole treated group was cured with significantly higher efficacy for the albendazole-flubendazole regimen. The laboratory data showed improvement in post-treatment phase especially for albendazole- flubendazole treated groups for hemoglobin\%, total leukocytic counts, neutrophil and lymphocyte counts that improved by time and a decline in the reported eosinophilia. The clinical data were significantly warning the presence of infection however they did not define the significance of treatment efficacy or resistance.

Conclusion: Enterobiasis is a childhood health problem with potential resistance to regular therapeutic protocols. Using albendazole- flubendazole combined regimen showed promising results in the treated groups superior to albendazole alone against resistant Enterobius vermicularis infection in children. This gives promising results encouraging further evaluation studies.
\end{abstract}

Keywords: Pinworm, Enterobius vermicularis, Flubendazole, Albendazole, Resistance.

\section{INTRODUCTION}

Enterobiasis is the most common parasitic helminth prevailing among children with estimated affection of one billion population worldwide. It has a prevalence rate of $4 \%$ to $28 \%$ among children worldwide causing distressing lifestyle and health problems ${ }^{(1,2)}$.

The life cycle from swallowing of eggs to adult worm maturity and passage of eggs again takes an average duration of 2 months ${ }^{(3)}$. The hosts' and food handlers' hands play important roles in transmitting the eggs and causing autoinfection ${ }^{(4)}$ and transmission of eggs to new hosts through contamination of food or drinks or shared towels and personal utensils. Also, the larvae can re-enter the anus and cause retrograde infection $^{(5)}$.

Socioeconomic factors including overcrowding and low personal hygiene and shared beds and utensils lead to increased infection rates among children and adults. The overcrowded families and communities with low health education increase the prevalence of infection due to direct transmission of infection and low compliance to treatment guidelines ${ }^{(\boldsymbol{\sigma})}$.

Most cases of enterobiasis are reported to be asymptomatic however the nocturnal perianal activity and laying off their sticky eggs lead to sleep disturbances and psychological distress ${ }^{(7,8)}$.

Pruritis ani or perianal itching is the cardinal symptom of infection while abdominal pain, diarrhea, and urinary manifestations especially in females are also present with associated vulvovaginal inflammation and scratching. Some cases are complicated with appendicitis due to invasion by adult worms of the lumen or peri- appendicular space ${ }^{(8)}$, with about $4 \%, 7 \%$ ${ }^{(7,8)}$, and $9.8 \%$ of children proved to have Enterobius worms in appendicular lumen among all pediatric appendectomies from Egypt, Ireland, Iran, and the USA respectively ${ }^{(\mathbf{9 , 1 0})}$, also reports about extra-intestinal involvement of internal organs are reported ${ }^{(11,12,13)}$. Also, Bayoumy et al. ${ }^{(\mathbf{1 4})}$ reported that the presence of $E$. vermicularis worms was observed in 4/200 (2\%) of appendectomy among Egyptian patients attending AlAzhar University Hospitals. 
Medical treatment of Enterobius vermicularis infection includes Albendazole Mebendazole, pyrantel pamoate, and to a lesser extent flubendazole and ivermectin. They are used in 2 doses 2 weeks apart to cover for the egg passage duration of the worms ${ }^{(8,15,16)}$.

Treatment-related side effects include headache, nausea, dizziness, metallic taste. Treatment failure is also reported (11-17). High doses of treatment are associated with more frequent and serious side effects especially encountered with albendazole high doses as pancytopenia, agranulocytosis, hepatic toxicity, and renal insult as mentioned in the French pharmacovigilance data analysis study ${ }^{(\mathbf{1 8})}$.

The empirical use of anthelminthic drugs without medical supervision and low compliance to treatment protocols lead to resistance to therapy. The development of new treatment protocols for resistant cases and national mass treatment campaigns with special attention to health education programs shall decrease the national burden of disease ${ }^{(\mathbf{2 0 , 2 1 , 2 2 )}}$.

The present study aimed to evaluate the efficacy of albendazole mass treatment alone compared to a combined albendazole-flubendazole regimen for treatment of recurrent and resistant Enterobius vermicularis infection in children.

\section{MATERIALS AND METHODS}

\section{Patients inclusion and Therapeutic Protocol:}

This study was carried out at the Pediatrics outpatient Clinic at Al-Azhar University Hospitals, and the Medical Parasitology Department at Damietta Faculty of Medicine, Al-Azhar University at New Damietta city, Egypt. Cases were recruited from multiple rural sites in Damietta and Gharbia Governorates in the period between November 2016 and February 2021. It was a clinical trial that included 130 children 3-12 years old with resistant Enterobius vermicularis infection determined by the following inclusion criteria for treatment resistance.

Counseling mothers attending clinics complaining of recurrent and or non-responsive treatment for enterobiasis among their children was done and they were invited to participate in the study. Accordingly, all mothers attending the meeting approved the clinical examination and laboratory investigation of the stool and blood samples as well as the treatment protocol of their children and family members including drug and sanitation requirements. Written informed consent was obtained from all the mothers whose children will participate in this study and from them and other family members as a mass treatment receiving according to explained methods.

All children underwent full history taking, clinical examination, perianal consented examination, and lab investigations including stool examination and complete blood count (CBC) pre and post-treatment at 2 and 8 weeks post-treatment. Family history of other sibling's infection was taken from mothers and the affected siblings were given the same group-specific treatment for children.

\section{Inclusion criteria:}

Children included in the study fulfilled inclusion criteria that included:

- The presence of Enterobius vermicularis infection for 2 months or more despite given mass treatment using a regular protocol of albendazole therapy that proved by stool samples examined to prove the presence of Enterobius vermicularis eggs.

- Absence of concurrent helminthic infection especially Ascaris lumbricoides.

- Absence of chronic diseases that needs closer monitoring during therapy or acute fulminant diseases that might have potential side effects due to possible drug interactions or adverse effects on affected organs.

\section{Samples Collection and examination:}

- Stool samples were collected from patients pretreatment and two and eight weeks posttreatment (including morning stool specimens and perianal swabs performed by cotton tip applicators and preserved in tubes containing 3 milliliters isotonic saline on the day of specimen collection). Samples were examined for Enterobius vermicularis and or other helminths eggs. Positive cases for concomitant helminth infections were excluded as described.

- Blood samples: $3 \mathrm{ml}$ of venous blood samples were collected from diseased children pretreatment and two and eight weeks post-treatment and healthy controls included in the study and placed in specific (EDTA) tubes containing anticoagulant for CBC with differential leukocytic count looking mainly for eosinophilia corresponded to levels above $400 / \mathrm{mm}^{3}$. This test was made by (Sysmex XP$300^{\mathrm{TM}}$ Automated Hematology Analyzer).

Children groups and therapeutic regimens: included children were classified counseled and included into groups randomly and given treatment as follows:

Group 1: treated with albendazole $100 \mathrm{mg} /$ day for 5 days followed by a consecutive dose after two weeks and four weeks from the end of the first dose.

Group 2: treated with albendazole $100 \mathrm{mg} /$ day for 5 days followed by two consecutive doses of flubendazole $200 \mathrm{mg} /$ day in two divided doses after two weeks and four weeks from the end of the first dose.

Repeated history taking, clinical examination, and lab investigations after two and eight weeks (stool and blood samples) from the beginning of therapy were done for all children included in both groups to detect therapeutic effectiveness. Mothers were also consented to have stool analysis for themselves and other siblings in the family as well however $30 \%$ of mothers only 
approved to do stool analysis while $90 \%$ of siblings did stool examination.

Sanitary education and standard precautions against recurrence of infection and family- siblings or adults infection were assured and revised with all mothers and their children (including trimming of nails, tight trousers, avoidance of perianal itching, frequent hand washing using soap and running water from toilet tab, mother hygienic hand washing after manipulating their children after toilets and bath showering, boiling of clothes and bed linens).

Treatment of adults in the family (excluding pregnant mothers): Mothers and eligible adults are given albendazole $200 \mathrm{mg}$ / day for three days (first dose) followed by second and third doses one week apart of $200 \mathrm{mg} /$ day (for one day only) in both groups.

Group 3: including 30 healthy children served as normal control with three consecutive stool samples examination without any parasitic infection or other diseases served as controls to exclude concurrent seasonal stool examination artifacts and to serve as a normal reference for blood counts normal range.

\section{Ethical considerations:}

Approval of the study was obtained from the Faculty of Medicine, Al-Azhar University (Damietta) institutional ethics committee (IRB). Informed written consent was obtained from parents of all children participating in the study, after explaining the objectives of the work.

\section{Data analysis}

Table (1): Comparison between Albendazole and Albendazole-flubendazole treatment groups demographic and clinical data.

\begin{tabular}{|c|c|c|c|c|c|c|c|}
\hline & & & Control & Albendazole & $\begin{array}{l}\text { Albendazole- } \\
\text { Flubendazole }\end{array}$ & Test & P-value \\
\hline \multirow[t]{2}{*}{ Sex } & \multicolumn{2}{|l|}{ Male } & $18(60.0 \%)$ & $37(56.9 \%)$ & $34(52.3 \%)$ & \multirow[t]{2}{*}{0.65} & \multirow[t]{2}{*}{0.75} \\
\hline & \multicolumn{2}{|l|}{ Female } & $12(40.0 \%)$ & $28(43.1 \%)$ & $31(47.7 \%)$ & & \\
\hline \multicolumn{3}{|l|}{ Age } & $7.10 \pm 2.70$ & $7.70 \pm 3.10$ & $7.23 \pm 2.80$ & 0.79 & 0.45 \\
\hline \multirow[t]{4}{*}{ Complaints } & \multirow{2}{*}{$\begin{array}{l}\text { Pruritis } \\
\text { ani }\end{array}$} & Present & 0 & $48(73.8 \%)$ & $50(76.9 \%)$ & \multirow[t]{2}{*}{0.166} & \multirow[t]{2}{*}{$<0.684$} \\
\hline & & Absent & 0 & $17(26.2 \%)$ & $15(23.1 \%)$ & & \\
\hline & \multicolumn{2}{|c|}{ Abdominal pain } & 0 & $43(66.2 \%)$ & $40(61.5 \%)$ & 0.300 & $<0.5084$ \\
\hline & \multicolumn{2}{|c|}{ Recurrent UTI } & 0 & $12(18.5 \%)$ & $13(20.0 \%)$ & 0.050 & $<0.824$ \\
\hline
\end{tabular}

Quantitative data were presented as mean \pm standard deviation (SD) and groups included compared by student (t) test. On the other side, categorical variables presented as frequency and percentages with groups compared by Chi-square test. P-value $<0.05$ was considered significant. All data processing and analysis were performed by statistical package for social sciences (SPSS) version 16 (SPSS Inc., Chicago, Illinois, USA).

\section{RESULTS}

The patients in both treatment groups including 65 children in the first $\left(1^{\text {st }}\right)$ group treated with albendazole alone and 65 children in the second $\left(2^{\text {nd }}\right)$ group treated with albendazole- flubendazole combination had an age distribution range from 3to 12 years with a mean and standard deviation of $7.70 \pm 3.10$ and $7.23 \pm 2.80$ for first and second groups respectively with no significant difference between them.

The patients included 37(56.9\%) \& 34(52.3\%) males and $28(43.1 \%) \& 31(47.7 \%)$ females in the first and second groups respectively with no significant difference between them. The patients' complaints included pruritis ani (48 out of 65 cases $\left(73.8 \%\right.$ ) in $1^{\text {st }}$ group and 50 out of 65 (76.9\%) in $2^{\text {nd }}$ group), abdominal pain $\left(43(66.2 \%)\right.$ in $1^{\text {st }}$ and $40(61.5 \%)$ in $2^{\text {nd }}$ group) and recurrent urinary tract infections with 12 out of 65 cases $(18.5 \%)$ in $1^{\text {st }}$ group and 13 out of $65(20.0 \%)$ in $2^{\text {nd }}$ group with no significant difference between them (Table 1). 
Laboratory data of both treatment groups revealed decreased basal, before treatment, hemoglobin percent $(\mathrm{Hb} \%)$ compared with control group hemoglobin percent gram per deciliter $(\mathrm{gm} / \mathrm{dl})$ mean and standard deviation being $11.85 \pm 0.48 \mathrm{gm} / \mathrm{dl}$ while it was $9.54 \pm 0.79 \mathrm{gm} / \mathrm{dl}$ in $1^{\text {st }}$ and $9.54 \pm 0.71$ $\mathrm{gm} / \mathrm{dl}$ in $2^{\text {nd }}$ group with significant difference between cases and controls.

The basal monitored elements of white blood cell count mean and standard deviation in first and second groups respectively were $4.74 \pm 0.76$ and $5.26 \pm 0.89$ for Total leucocyte count compared to $6.36 \pm 1.12$ in controls with significant difference between cases and controls. For Neutrophil counts $1.83 \pm 0.28$ and $1.89 \pm 0.15$ compared to $3.30 \pm 0.42$ in controls with significant difference between cases and controls, for lymphocyte count means were $2.53 \pm 0.16$ and $2.43 \pm 0.29$ compared to $4.79 \pm 0.69$ in controls with significant difference between cases and controls, for Eosinophil count mild eosinophilia were present in 21 of $65(32.3 \%)$ in $1^{\text {st }}$ group and $15(23.1 \%)$ in $2^{\text {nd }}$ group while only 1 out of 30 (3.3\%).controls had mild eosinophilia. Moderate eosinophilia was reported in 11 of $65(16.9 \%)$ in the $1^{\text {st }}$ group and 6 out of $65(9.2 \%)$ in the $2^{\text {nd }}$ group with no cases among controls with a significant increase in eosinophilia among cases compared to controls.

In the treatment groups, 36 out of $65(55.4 \%)$ children in the albendazole treated group and 54 out of $65(83.1 \%)$ children in the albendazole-flubendazole treated group were cured compared to $29(44.6 \%)$ out of 65 children and 11 out of $65(16.9 \%)$ children in the first and second groups respectively were resistant to treatment with positive stool analysis for Enterobius vermicularis eggs after 2 months of therapy with statistically significant difference between them (Table 2).
The post-treatment monitored elements of hemoglobin and white blood cells counts means and standard deviation in first and second groups respectively showed a rise in $\mathrm{Hb} \%$ in both groups with means and standard deviation of $9.54 \pm 0.80$ after 2 weeks and $9.68 \pm 0.74$ after 8 weeks in $1^{\text {st }}$ and $9.63 \pm 0.74$ after 2 weeks and $9.83 \pm 0.75$ after 8 weeks for $\mathrm{Hb} \%$ in the $2^{\text {nd }}$ group with no significant difference between them.

Regarding levels of white blood cells, the total leucocytic count of the $1^{\text {st }}$ group was 5.85 \pm 1.18 after 2 weeks and $5.67 \pm 1.14$ after 8 weeks compared to $6.27 \pm 1.15$ after 2 weeks and $6.34 \pm 1.15$ after 8 weeks in $2^{\text {nd }}$ group with significant difference improvement more after 8 weeks duration, for post-treatment Neutrophil counts of the $1^{\text {st }}$ group was $1.93 \pm 0.29$ after 2 weeks and $2.00 \pm 0.32$ after 8 weeks compared to $2.17 \pm 0.15$ after 2 weeks and $2.43 \pm 0.29$ after 8 weeks in $2^{\text {nd }}$ group with significant difference improvement more in the $2^{\text {nd }}$ group.

The post-treatment lymphocytic counts mean in the $1^{\text {st }}$ group was $2.63 \pm 0.19$ after 2 weeks and $2.77 \pm 0.25$ after 8 weeks compared to $2.77 \pm 0.34$ after 2 weeks and $2.92 \pm 0.37$ after 8 weeks in the $2^{\text {nd }}$ group with significant difference improvement more in the $2^{\text {nd }}$ group.

For eosinophilic count, mild eosinophilia improved after 2 and 8 weeks of therapy in $1^{\text {st }}$ group and also in the $2^{\text {nd }}$ group to $18(27.7 \%) \& 15(23.1 \%)$ and $13(20.8 \%) \& 11(16.2 \%)$ with $3(10 \%)$ case among controls. Moderate eosinophilia showed little or no improvement in the $1^{\text {st }}$ group with mild improvement in the $2^{\text {nd }}$ group to $12(18.5 \%) \& 15(23.1 \%)$ and $4(6.2 \%)$ \& 5(7.7\%) with no cases among controls with significant difference between cases and controls regarding eosinophilia. 
Table (2): Comparison between Albendazole and Albendazole- flubendazole treatment groups pre and post-treatment laboratory data

\begin{tabular}{|c|c|c|c|c|c|c|c|}
\hline Item & \multicolumn{2}{|r|}{ Group } & Control & Albendazole & $\begin{array}{l}\text { Albendazole- } \\
\text { Flubendazole }\end{array}$ & Test & P-value \\
\hline \multirow[t]{3}{*}{ Hemoglobin } & \multicolumn{2}{|l|}{ Basal } & $11.85 \pm 0.48$ & $9.54 \pm 0.79$ & $9.54 \pm 0.71$ & 128.46 & $<0.001 *$ \\
\hline & \multicolumn{2}{|c|}{ Two weeks after treatment } & & $9.54 \pm 0.80$ & $9.63 \pm 0.74$ & 0.45 & 0.50 \\
\hline & \multicolumn{2}{|c|}{ Eight weeks after treatment } & & $9.68 \pm 0.74$ & $9.83 \pm 0.75$ & 1.26 & 0.26 \\
\hline \multirow[t]{6}{*}{ Eosinophilia } & \multirow[t]{2}{*}{ Basal } & Mild & $1(3.3 \%)$ & $21(32.3 \%)$ & $15(23.1 \%)$ & \multirow[t]{2}{*}{19.74} & \multirow[t]{2}{*}{$0.001 *$} \\
\hline & & Moderate & $0(0.0 \%)$ & $11(16.9 \%)$ & $6(9.2 \%)$ & & \\
\hline & \multirow{2}{*}{$\begin{array}{l}\text { Two } \\
\text { weeks }\end{array}$} & Mild & $1(3.3 \%)$ & $18(27.7 \%)$ & $13(20.8 \%)$ & \multirow[t]{2}{*}{21.42} & \multirow[t]{2}{*}{$<0.001 *$} \\
\hline & & Moderate & $1(3.3 \%)$ & $12(18.5 \%)$ & $4(6.2 \%)$ & & \\
\hline & \multirow{2}{*}{$\begin{array}{l}\text { Eight } \\
\text { weeks }\end{array}$} & Mild & $3(10.0 \%)$ & $15(23.1 \%)$ & $11(16.2 \%)$ & \multirow[t]{2}{*}{17.38} & \multirow[t]{2}{*}{$0.002 *$} \\
\hline & & Moderate & $0(0.0 \%)$ & $15(23.1 \%)$ & $5(7.7 \%)$ & & \\
\hline \multirow[t]{3}{*}{ WBCs } & \multicolumn{2}{|l|}{ Basal } & $6.36 \pm 1.12$ & $4.74 \pm 0.76$ & $5.26 \pm 0.89$ & 33.6 & $<0.001 *$ \\
\hline & \multicolumn{2}{|c|}{ Two weeks after treatment } & - & $5.85 \pm 1.18$ & $6.27 \pm 1.15$ & 4.15 & $0.044^{*}$ \\
\hline & \multicolumn{2}{|c|}{ Eight weeks after treatment } & - & $5.67 \pm 1.14$ & $6.34 \pm 1.15$ & 11.15 & $0.001^{*}$ \\
\hline \multirow[t]{3}{*}{ Neutrophiles } & \multicolumn{2}{|l|}{ Basal } & $3.30 \pm 0.42$ & $1.83 \pm 0.28$ & $1.89 \pm 0.15$ & 335.0 & $<0.001 *$ \\
\hline & \multicolumn{2}{|c|}{ Two weeks after treatment } & & $1.93 \pm 0.29$ & $2.05 \pm 0.19$ & 7.31 & $0.008^{*}$ \\
\hline & \multicolumn{2}{|c|}{ Eight weeks after treatment } & & $2.00 \pm 0.32$ & $2.17 \pm 0.15$ & 16.22 & $<0.001 *$ \\
\hline \multirow[t]{3}{*}{ Lymphocytes } & \multicolumn{2}{|l|}{ Basal } & $4.79 \pm 0.69$ & $2.53 \pm 0.16$ & $2.43 \pm 0.29$ & 492.5 & $<0.001 *$ \\
\hline & \multicolumn{2}{|c|}{ Two weeks after treatment } & & $2.63 \pm 0.19$ & $2.77 \pm 0.34$ & 8.07 & $0.005^{*}$ \\
\hline & \multicolumn{2}{|c|}{ Eight weeks after treatment } & & $2.77 \pm 0.25$ & $2.92 \pm 0.37$ & 7.22 & $0.008^{*}$ \\
\hline \multirow{2}{*}{$\begin{array}{l}\text { Treatment } \\
\text { efficacy }\end{array}$} & \multicolumn{2}{|l|}{ Cured } & & $36(55.4 \%)$ & $54(83.1 \%)$ & \multirow[t]{2}{*}{11.70} & \multirow[t]{2}{*}{$0.001^{*}$} \\
\hline & \multicolumn{2}{|c|}{ Resistance } & & $29(44.6 \%)$ & $11(16.9 \%)$ & & \\
\hline
\end{tabular}

Table 3 showed that 22 out of $71(30.9 \%)$ males and 18 out of $59(30.5 \%)$ females still had infection after the end of therapy with positive stool samples for Enterobius vermicularis.

There was no significant difference between males and females regarding treatment efficacy in both groups however female children were slightly higher than males to present with recurrent or resistant enterobiasis. The patient's complaints including pruritis ani, abdominal pain, and recurrent urinary tract infections did not show a significant correlation regarding total resistance or effectiveness of therapy as they were as a marker for suspected Enterobius vermicularis infection compared to normal controls. 
Table (3): Correlation between Treatment efficacy and clinical manifestations.

\begin{tabular}{|c|c|c|c|c|c|c|}
\hline \multirow{3}{*}{ Sex } & & & Resistant & Non-Resistant & Test & P-value \\
\hline & \multicolumn{2}{|l|}{ Male } & $22 / 71$ & $49 / 71$ & \multirow[t]{2}{*}{0.003} & \multirow[t]{2}{*}{0.95} \\
\hline & \multicolumn{2}{|l|}{ Female } & $18 / 59$ & $41 / 59$ & & \\
\hline \multirow{6}{*}{ Complaints } & \multirow{2}{*}{ Pruritis ani } & Present & 33 & 65 & \multirow[t]{2}{*}{1.576} & \multirow[t]{2}{*}{0.209} \\
\hline & & Absent & 7 & 25 & & \\
\hline & \multirow[t]{2}{*}{ Abdominal pain } & Present & 25 & 58 & \multirow[t]{2}{*}{.045} & \multirow[t]{2}{*}{0.831} \\
\hline & & Absent & 15 & 32 & & \\
\hline & \multirow[t]{2}{*}{ Recurrent UTI } & Present & 9 & 16 & \multirow[t]{2}{*}{.398} & \multirow[t]{2}{*}{0.528} \\
\hline & & Absent & 31 & 74 & & \\
\hline
\end{tabular}

\section{DISCUSSION}

The high prevalence rates of Enterobius vermicularis infection and its worldwide distribution needs more studies to evaluate new therapeutic options. Having distressing effects due to lack of sleep resulting from its nocturnal perianal activity and female urinary tract infection and suspicious involvement in pediatrics appendicitis leads to low school performance and psychological upsets in affected children. Addressing the management of Enterobius vermicularis in children with new therapeutic regimens shall decrease the burden of disease and increases the safety of drugs used ${ }^{(\mathbf{1 7}, 19)}$.

In our study, the age distribution of included children ranged from 3to 12 years with a mean and standard deviation of $7.70 \pm 3.10$ and $7.23 \pm 2.80$ for first and second groups respectively with no significant difference between them. This comes in accordance with multiple studies that reported that children between 3 and 12 years are mostly affected by Enterobius vermicularis with a low level of infection below 2 years and above 12 years ${ }^{(\mathbf{1 7})}$. Also Abdel Aziz et al. ${ }^{(22)}$. noted a prevalence rate of 5.4\% among children aged 3-14 years in Damietta governorate. Bayoumy et al. ${ }^{(23)}$ identified a prevalence of enterobiasis as $11.8 \%$ among children aged from $(6-12)$ years in a rural area at Beheira, Egypt. This comes in accordance with some European studies that reported a little to higher prevalence among Norwegian, Swedish, Estonian, and Romanian studies $(24,25,26,27)$. The latter found lower infection rates in children below 2 years and above 14 years of age ${ }^{(27)}$.

The patients included 37(56.9\%) \& 34(52.3\%) males and $28(43.1 \%) \& 31(47.7 \%)$ females in the first and second groups respectively with no significant difference between them. This is also in accordance with El Kutry and Sopeah ${ }^{(19)}$ study where Girls $(20.31 \%)$ had a lower prevalence than boys $(24.5 \%)$ this was also reported in almost all studies $(\mathbf{2 2 , 2 3 , 2 4 , 2 5 , 2 6 , 2 7 )}$.

The patient's complaints included pruritis ani (48 out of 65 cases $(73.8 \%)$ in $1^{\text {st }}$ group and 50 out of 65 $(76.9 \%)$ in $2^{\text {nd }}$ group), abdominal pain $\left(43(66.2 \%)\right.$ in $1^{\text {st }}$ and $40(61.5 \%)$ in $2^{\text {nd }}$ group) and recurrent urinary tract infections with 12 out of 65 cases $(18.5 \%)$ in $1^{\text {st }}$ group and 13 out of $65(20.0 \%)$ in $2^{\text {nd }}$ group with no significant difference between them. Many studies put anal scratching as a pronounced risk factor for the spread and recurrence of infection among children due to the adhesive nature of eggs to hands and nails that will be transferred directly to the mouth and indirectly through utensils among household family members and kindergarten children ${ }^{(28,29,30)}$.

Laboratory data of both treatment groups revealed mildly increased basal eosinophil count while decreased basal, before treatment, hemoglobin percent $(\mathrm{Hb} \%)$ compared with the control group with significant difference between cases and controls. Also, basal monitored elements of white blood cells count for Total leucocytic and neutrophilic as well as lymphocytic counts were significantly lower than controls. Kutry and Sopeah ${ }^{(19)}$ study as well as Bayoumy et al. ${ }^{(23)}$, also reported a significant decline of Hb levels, WBC's, and RBCs count among children infected with enterobiasis pre- treated compared to healthy children in the control group.

In treatment groups cure was achieved in 54 out of $65(83.1 \%)$ children in albendazole- flubendazole treated group compared to 36 out of $65(55.4 \%)$ children in albendazole treated group with significant favorable outcomes in albendazole flubendazole regimen. Kutry and Sopeah ${ }^{(19)}$ used Sidr extracts to treat nonresistant infections with pinworms and achieved significant improvement compared to the mebendazole-treated group. Our study therapeutic approach of albendazoleflubendazole combination regimen overcomes the need for a high dose albendazole therapy recommended in many studies reaching up to $400 \mathrm{mg} /$ day for children and $8000 \mathrm{mg} /$ day for adults of albendazole with repeated doses after 14 and 28 days intervals with their potentially dangerous side effects ${ }^{(\mathbf{1 5}, \mathbf{1 7}, \mathbf{1 8})}$.

The post-treatment monitored elements of hemoglobin and white blood cells counts showed a rise in $\mathrm{Hb} \%$ and leukocyte total and differential counts in both treatment groups with a significant increase compared to pretreatment levels however still not reaching control levels ensuring the need for vitamins minerals and other supplementations. Eosinophilia reported in the pretreatment phase decreased gradually in two and 8 weeks results more in the albendazoleflubendazole treatment group. This comes in accordance with results of Bayoumy et al. ${ }^{(23)}$ that reported a significant correlation in the white blood cell counts and the presence of enterobiasis, (80\%) of the affected children and children, after treating with Sidr extracts having improved significantly in $(\mathrm{Hb}, \mathrm{RBC}$ 's, and WBC 's) levels compared to pre-treatment. Also, Kutry and Sopeah ${ }^{(19)}$, declared that parameters of blood $(\mathrm{Hb}$, 
RBCs, and WBCs) were improved significantly after treatment.

Patients with persistent infection, 11 out of $65(16.9 \%)$ and $29(44.6 \%)$ out of 65 children in the first and second groups respectively with symptoms like abdominal pain and perianal itching, and urinary tract infections in females denote the need to control nonsupervised and non-compliant treatment for Enterobius vermicularis as well as other helminth infections that will need repeated albendazoleflubendazole therapy or newly introduced therapy as mebendazole or natural extracts like Sidr and other plants extracts. Mass treatment protocols for cases and national eradication campaigns, as well as health education, needs periodic update and communication of proper hygienic and health promotion measures. The favorable and significant outcomes of the albendazoleflubendazole regimen gives a potentially efficient therapeutic approach that needs further evaluation to be adopted in the treatment of Enterobius vermicularis infection in resistant and nonresistant cases.

\section{REFERENCES}

1. Vleeschouwers W, Hofman P, Gillardin J et al. (2013): Appendicitis-like clinical image elicited by Enterobius vermicularis: case report and review of the literature. Acta Chir Belg., 113(2):139-42.

2. Kucik C, Martin G, Sortor B (2004): Common intestinal parasites. Am Fam Physician, 69(5):1161-8.

3. Bynum W, Porter A, Roy E (2013): Companion Encyclopedia of the History of Medicine. Routledge., 43 (5): 358-363.

4. Cranston I, Potgieter N, Mathebula S et al. (2015): Transmission of Enterobius vermicularis eggs through hands of school children in rural South Africa. Acta Trop., 150: 946.

5. Schüffner W, Swellengrebel N(1949): A newly discovered mode of infection with Enterobius vermicularis. J Parasitol., 35: $138-46$.

6. Deplazes P, Eckert J, von Samson-Himmelstjerna G et al. (2013): Lehrbuch der Parasitologie für die Tiermedizin. Acta Vet Hung., 61(1):147-8.

7. Kubiak K, Dzika E, Paukszto L (2017): Enterobiasis epidemiology and molecular characterization of Enterobius vermicularis in healthy children in north-eastern Poland. Helminthologia, 54: 284-91.

8. Yang C, Liang C, Lin C et al. (2017): Impact of Enterobius vermicularis infection and mebendazole treatment on intestinal microbiota and host immune response. PLoS Negl Trop Dis., 11(9): 5963-70.

9. Fleming C, Kearney D, Moriarty $P$ et al. (2015): An evaluation of the relationship between Enterobius vermicularis infestation and acute appendicitis in a pediatric population- A retrospective cohort study. International Journal of Surgery, 18; 154-158.

10. Zouari M, Louati H, Abid I et al. (2018): Enterobius vermicularis: A Cause of Abdominal Pain Mimicking Acute Appendicitis in Children. A Retrospective Cohort Study. Archives of Iranian Medicine, 21(2): 67-72.

11. Arca M, Gates R, Groner $J$ et al. (2004): Clinical manifestations of appendiceal pinworms in children: an institutional experience and a review of the literature. Pediatr Surg Int., 20:372-375.
12. Tornieporth $\mathbf{N}$, Disko $\mathrm{R}$, Brandis A et al. (1992): Ectopic Enterobiasis: a case report and review. J Infect., 24: 87-90.

13. Powell G, Sarmah P, Sethi B et al. (2013): Enterobius vermicularis infection of the ovary.. https://pubmed.ncbi.nlm.nih.gov/24177459/

14. Bayoumy A, Seif Elnasr A, Ibrahim A et al.(2018): Role of parasitic infection in adult patients with acute appendicitis. The Egyptian Journal of Hospital Medicine. 70 (12), 2050-2057.

15. Georgiev V (2001): Chemotherapy of Enterobiasis (Oxyuriasis). Expert Opin Pharmacother., 2: 267-75.

16. Schenone H, Galdames $M$ et al. (1977): Flubendazole in the treatment of intestinal nematode infections in children. Boletin Chileno de Parasitologia, 32(3/4): 85-86.

17. Wendt S, Trawinski H, Schubert S et al. (2019): The Diagnosis and Treatment of Pinworm Infection. Dtsch Arztebl Int., 116(13): 213-219.

18. Simiand E, Montastruc J, Magnaval J (2004): Adverse Drug Reactions to Anthelmintics. Annals of Pharmacotherapy, 38(3):383-8.

19. El Kutry M, Sopeah H (2020): Impact of Intake a Sidr (Zizyphus Spina-Christi L.) Extract on Enterobiasis Vermicularis Infection for Children. Biomedical \& Pharmacology Journal, 13(1): 359-366.

20. Abeer M, Reem H (2009): Effect of Sidr (Zizyphus SpinaChristi) Fruit Extract on the Central Nervous System in Male Albino Rats. American-Eurasian Journal of Scientific Research, 4(4): 263-267.

21. Mohammed A (2016): Characterization and Biological Activity Study of Ziziphus Spina-Christi Seed Oil. Sudan University of Science and Technology, College of Science, Pp. 51. http://repository.sustech.edu/handle/123456789/14811

22. Mohammad K, Mohammad A, Abu El-Nour M et al. (2012): The prevalence and associated risk factors of intestinal parasitic infections among school children living in rural and urban communities in Damietta Governorate, Egypt. Academia Arena, 4(5):90-97.

23. Bayoumy A, Abd El Raheem N, Abo Hashim A et al. (2018): Parasitic Profile among Primary School Children in A Rural Area at Beheira Governorate, Egypt. The Egyptian Journal of Hospital Medicine, 70(12): 2042-2049.

24. Bøås H, Tapia G, Sødahl J et al. (2012): Enterobius vermicularis and risk factors in healthy Norwegian children. Pediatr Infect Dis J., 31: 927-30.

25. Herrström P, Henricson K, Råberg A et al. (2001): Allergic disease and the infestation of Enterobius vermicularis in Swedish children 4-10 years of age. J Investig Allergol Clin Immunol., 11: 157-60.

26. Remm M (2006): Distribution of Enterobiasis among nursery school children in SE Estonia and of other helminthiases in Estonia. Parasitol Res., 99: 729-36.

27. Neghina $R$, Dumitrascu V, Neghina A et al. (2013): Epidemiology of ascariasis, Enterobiasis and giardiasis in a Romanian western county (Timis), 1993-2006. Acta Trop., 125: 98-101.

28. Burkhart C, Burkhart C (2005): Assessment of frequency, transmission, and genitourinary complications of Enterobiasis (pinworms). Int J Dermatol., 44: 837-40.

29. Cook G (1994): Enterobius vermicularis infection. Gut, 35: 1159-62.

30. Cranston I, Potgieter N, Mathebula S et al. (2015): Transmission of Enterobius vermicularis eggs through hands of school children in rural South Africa. Acta Trop., 150: 946. 